\title{
Shear strength of reinforced concrete beams strengthened by P.B.O. fiber mesh under loading
}

\author{
Zinoviy Blikharskyy ${ }^{1}$, Roman $\mathrm{Khmil}^{1^{*} \text {, and Pavlo Vegera }}{ }^{1}$ \\ ${ }^{1}$ Lviv Polytechnic National University, Department of Building Constructions and Bridges, Bandera \\ str. 13, Lviv, Ukraine, 79013
}

\begin{abstract}
This article presents experimental study of sheer strength of reinforced concrete beams without transverse steel reinforcement, which strengthened by composite materials. The feature of tests is that the beams' strengthening is made under simultaneous action of loading. The research program involves a series of test beams with size $2100 \times 200 \times 100 \mathrm{~mm}$ and which contains control sample and three reinforced samples by reinforcing FRCM system. FRCM system consisting of two components: mineral mortar based on modified cement Ruredil X Mesh M750 and reinforcing P.B.O. fiber mesh Ruredil X Mesh Gold (Italy). The strength research of test samples was carried out with the shear distance to effective depth ratio $a / d=2$. The strengthening loading levels were selected at 0.0 , $0.3,0.5$ from shear strength of non strengthened control sample. As a result of experimental studies we found that during strengthening design the inclined cross section of beams we should take into account the existing level of loading. Using the strengthening system Ruredil X Mesh Gold the strengthening effect is reduced at 2.8 to 2.9 times while the existing level of loading increase from 0 to $50 \%$.
\end{abstract}

\section{Introduction}

Nowadays, many industrial and civil buildings have already exceeded their estimated lifetime. Corrosive influence leads to significant corrosion damage of reinforcement of the constructions, sometimes even to its full destruction. Demolition costs for these buildings or new construction costs are extremely high. Therefore we consider strengthening of old structures to continue their lifetime and bring them in accordance with the requirements of actual codes and standards.

A lot of studies of shear strength of concrete structures have been conducted, concerning the study of stress-strain state design principles, methods of strengthening using steel or concrete elements. Using a significant amount of consumables leads to finding the strengthening material, which would have provided high shear strength increasing of RC beams with lower cost of labor [1-2]. The composite materials made from carbon composite and others fibers in a cloth or ribbons belong to these materials. The simplicity and quickness of installation of the reinforcement allows us to gain good results without major delays.

* Corresponding author: roman.y.khmil@lpnu.ua 
Analysing researches of shear strength with different types of composite materials reinforcing, it can be concluded that the study of stress-strain state of shear reinforced is a key issue, with ongoing development goals and objectives, which are set by the researchers [3-5]. However, few studies are conducted on reinforced beams under simultaneous action loading and reinforcing. Therefore, the establishment of real sheer strength of RC beams with damaged sheer reinforcing and strengthened by composite materials under action of loading is a topical scientific and practical issue.

\section{The testing program}

In this article we research the beams without transverse reinforcement, which serve as a beams model with full destructive stirrups after corrosion influence. The research program involves a one series of test beams with size $2100 \times 200 \times 100 \mathrm{~mm}$ which contains control sample and three reinforced samples by reinforcing FRCM system. FRCM system consisting of two components: mineral mortar based on modified cement Ruredil X Mesh M750 and reinforcing P.B.O. fiber mesh Ruredil X Mesh Gold (Italy) [6].

The strength research of test samples was carried out with the shear distance to effective depth ratio $a / d=2$. The strengthening loading levels were selected at $0.0,0.3,0.5$ from shear strength $\left(V_{e d}\right)$ of non-strengthened control sample.

$\mathrm{RC}$ beams designed that the beams destruction after strengthening took place by shear. To accomplish it these beams were designed with a significant margin of tensile rebar. A method of experimental research involves alternate testing of two inclined sections of reinforced concrete beams, which reduces the cost of materials and necessary instrumentation and detailed presented at [7].

\section{Experimental study of shear strength}

\subsection{Research results of control beams}

At the first stage of research, control sample was tested. Beams mark follows BO - beam ordinary, the first digit - serial number, the second digit - prototypes number and the third digit - section number. For example, BO 1.2-2 means that tested example from the first series of the second beam of the second section.

The limit value of concrete compressed deformation at cross section above the inclined crack was taken as the criterion of shear strength $[8,9]$. The shear strength of the RC beams equated with physical destruction of compressed concrete above the inclined cracks. Both limit states (ULS and SLS) of control beam occur in the following sequence:

- crushing compressed concrete and plastic deformation of reinforcement cage (ULS).

- $\quad$ opening limit width of the inclined crack $\left(w_{\max }=0.4 \mathrm{~mm}\right)$ in concrete (SLS);

The first inclined crack disclosed in mid-height cross section, at the load $-50 \mathrm{kN}$ at an angle equal to $45^{\circ}$. At the next stage the inclined crack spread to the bottom surface of the beam. With increasing loading the width of crack increased and the crack propagation occurred to the top surface of the control sample (Fig. 1). 


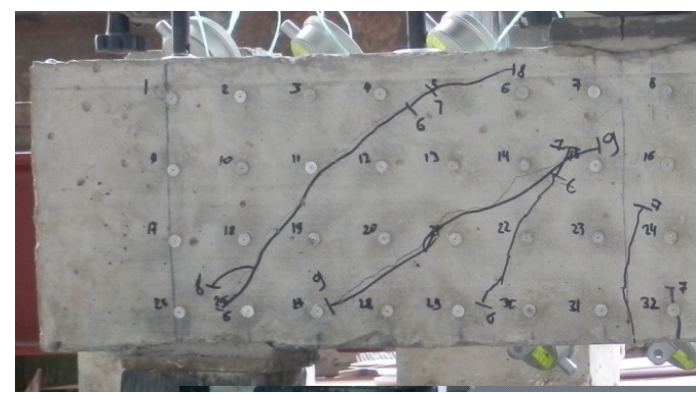

Fig. 1. Distribution of inclined cracks in the control sample.

On occurrence of limit width of crack $\mathrm{w}_{\max }=0.4 \mathrm{~mm}$, another crack was opened in the direction from the loading point to the edge of beam support. This crack was destructive one. Inclined crack spread throughout the height of the beam, then occurred the crushing of compressed concrete. Longitudinal tensile reinforcement received typical plastic bending deformations. Shear strength of $\mathrm{RC}$ beams BO-1.1 was $\mathrm{V}_{\text {ed }}=95 \mathrm{\kappa N}$. General view of the tested control beam is shown in Fig. 2.

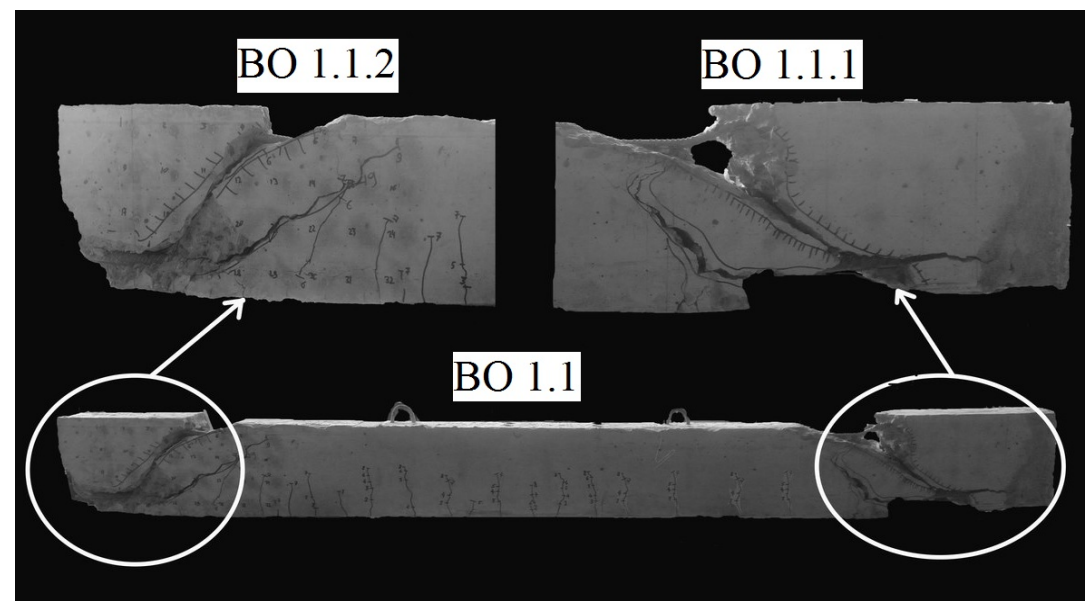

Fig. 2. The tested control beam BO-1.1

For each cross section of test specimen at shear area there was obtained area of distribution concrete deformation by using rappers of the comparator measurement (Fig 3).

a)

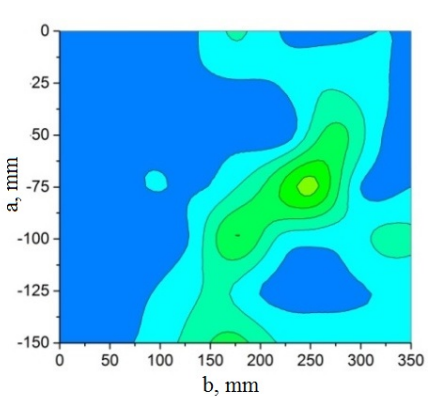

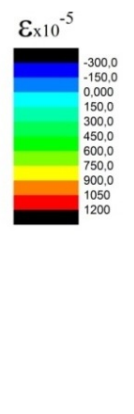

b)
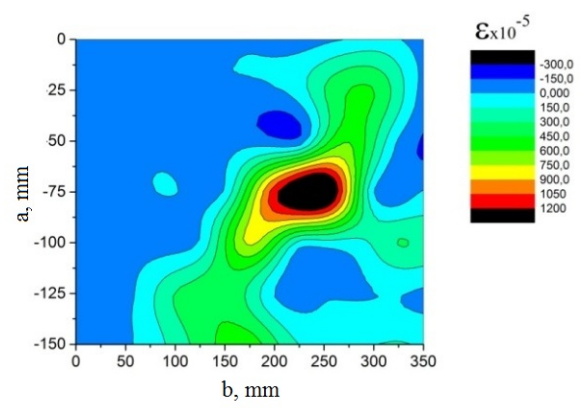

Fig.3. The distribution of concrete deformation in the shear area for beam BO-1.1: a) the area before the opening inclined crack; b) the area before the exhaustion of ULS 
Measurement of concrete deformation was performed using rappers of comparator with grid spacing $50 \times 50 \mathrm{~mm}$. Grid frame of comparator located on the front edge of specimen (Fig. 2). The distance between the rappers were measured with an accuracy of $0.1 \mathrm{~mm}$.

Tensile deformations fixed with cracks width in concrete. This method of measurements provides a distribution of strains from the support point to the loading point. As we can see (Fig. 3b) the tensile deformations are in the direction of distribution inclined cracks, and compression deformations are around them.

\subsection{Results of the study of strengthened beams}

According to the testing program, three specimens were strengthened by reinforcing FRCM system with $70 \mathrm{~mm}$ wide strips (Fig. 4-6). These beams mark follows BSC - beam strengthened by composite material; the first digit - serial number, the second digit prototypes number and the third digit - section number. Index $0 \ldots .0 .5$ means the loading level under which the strengthening was performed and defined from shear strength $\left(\mathrm{V}_{\mathrm{ed}}\right)$ of non-strengthened control sample.

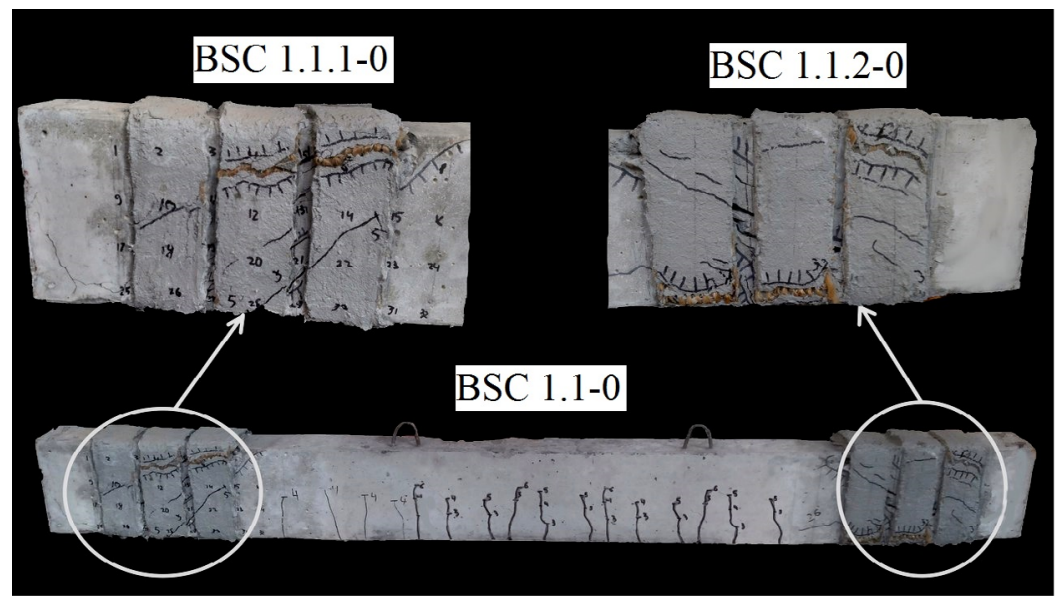

Fig. 4. The tested strengthened beam BSC 1.1-0

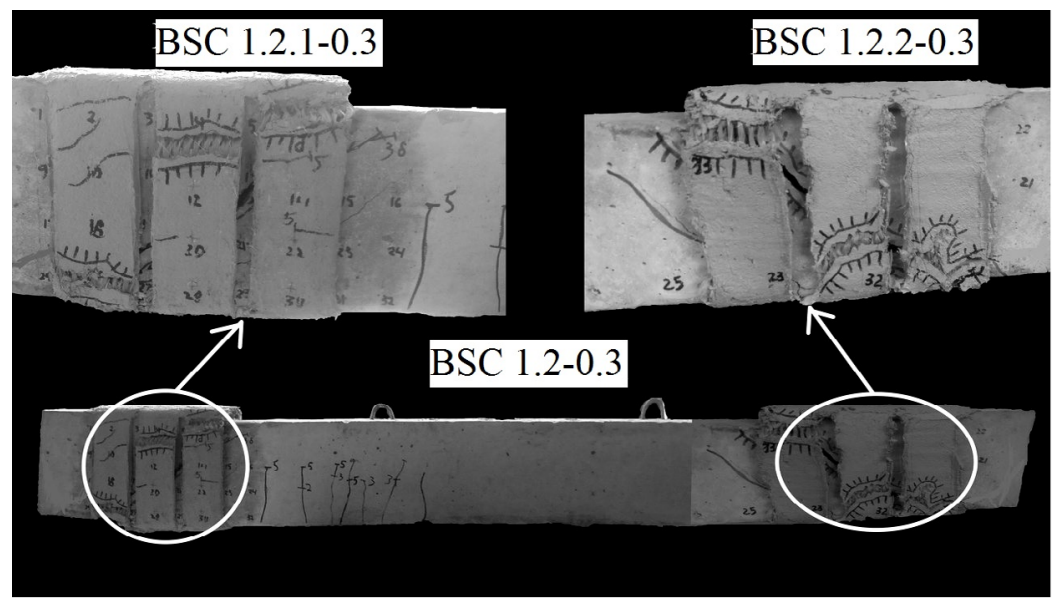

Fig. 5. The tested strengthened beam BSC 1.2-0.3 
The criterion of achievement shear strength was the same as for the control sample. The shear destruction of $\mathrm{RC}$ beams strengthened by composite materials took place in the following order:

- opening limit width $w_{\max }=0.4 \mathrm{~mm}$ of inclined crack on the concrete surface;

- distribution inclined crack to the compressed concrete and appearance mesh of cracks with width $w_{\max }=0.2 \mathrm{~mm}$ on the surface of strengthening system;

- concrete damage in the area of the main tensile stress and exfoliation strengthening system in this area;

- plastic deformation of rebar and crushing of compressed concrete, large deformation reinforcing materials, which can be seen due to the damage of the cover layer.

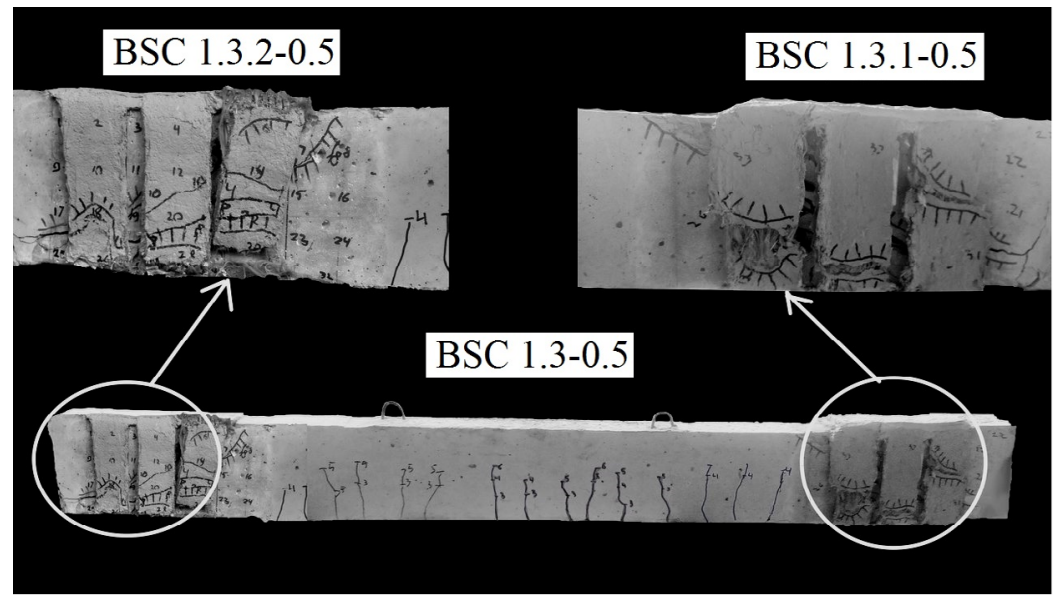

Fig. 6. The tested strengthened beam BSC 1.3-0.5

With further increasing loading the materials detachment from beam continues and there occurs a violation of anchoring. The shear strength of samples strengthened without any loading was amounted to $V_{E d}=137.5 \mathrm{kN}$. Average shear strength for samples strengthened with some loading level were: for beam BSC 1.2-0.3 $-V_{E d}=120 \mathrm{kN}$ and for BSC $1.3-0.5-V_{E d}=110 \mathrm{kN}$.

A type of fracture was changed in strengthened beams, it was more plastic, without any concrete particles and plastic deformation of steel reinforcement cage. The distribution of concrete deformations is shown in Fig. 7. As we can see, the tensile deformations occupy a larger area.

For the sample strengthened without initial loading, stress concentration was held at half of the beam height, similar to the control sample. Samples, strengthened with some initial loading, have another type of stress distribution that is caused by the inclusion strengthening materials at working similar to the transverse steel reinforcement.

Concrete deformation with a width of opening inclined cracks, the nature of the growth are the same as for the control samples but reach much higher values. With the exhaustion of shear strength, strengthening materials received significant deformation, which led to the loss of its original appearance, but the gap was not observed.

According to recommendation [10] the deformation of composite materials should be $40 \%$ of its limit tensile deformation. What we can see according to experimental data, this type of FRCM system strengthening is effective one for shear strengthening. 
a)
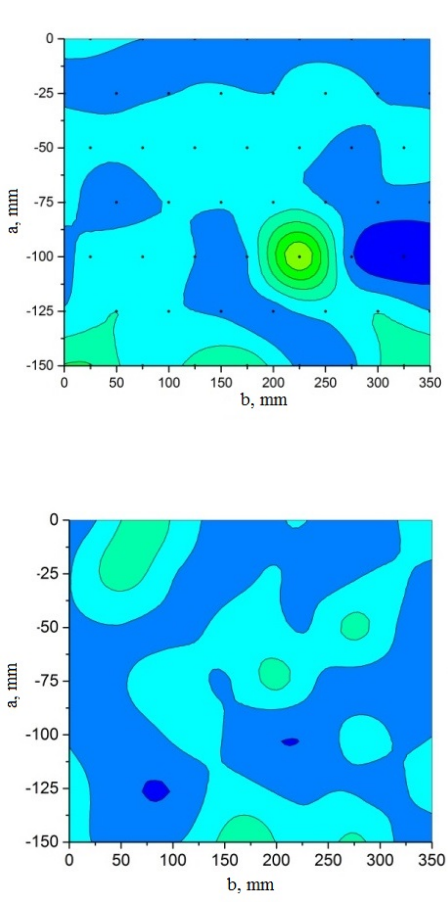

c)

e)

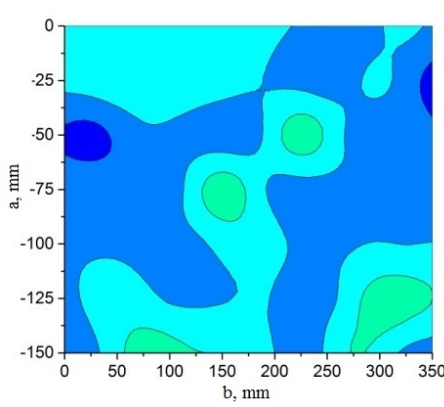

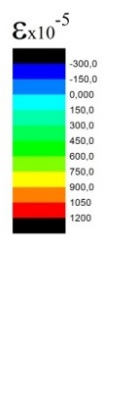

b)
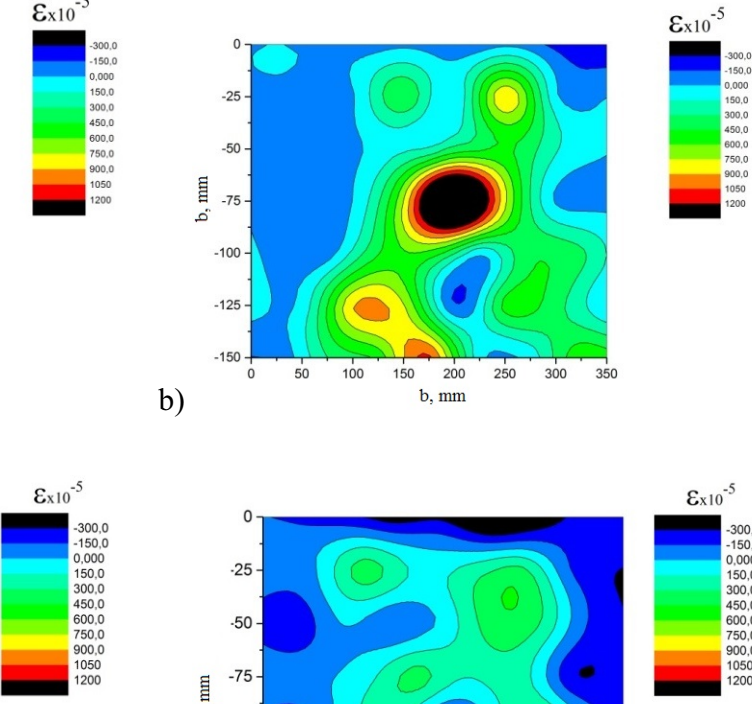

d)
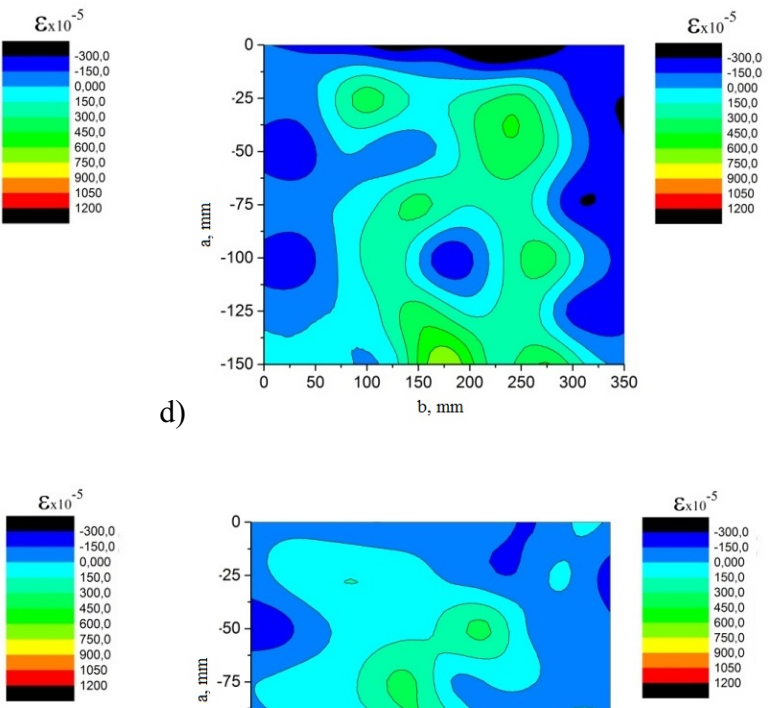

f)
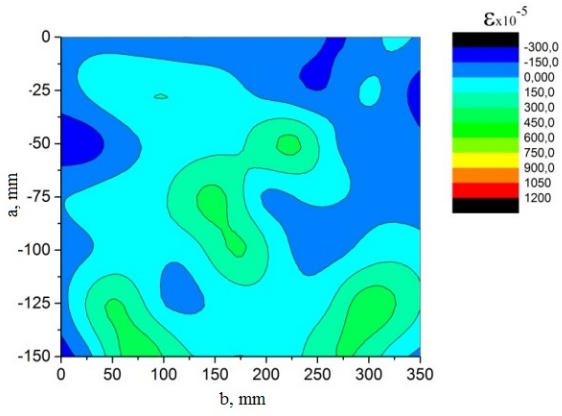

Fig.7. The distribution of strain in the beam: area of deformation before opening inclined cracks in the beam: a) BSC 1.1-0; c) BSC 1.2-0.3; e) BSC 1.3-0.5; area of deformation before exhaustion of ULS for beams: b) BSC 1.1-0; d) BSC 1.2-0.3; f) BSC 1.3-0.5

\subsection{Analysis of experimental results}

The maximum effect of increasing the shear strength was $45 \%$ for samples strengthened without initial loading. It should be noted that with increasing loading level up to 0.5 of shear strength of control beam $\left(0.5 V_{e d}\right)$ the effect of strengthening decreased to $16 \%$. For beams reinforced at the level of $0.3 \cdot$ effect decreases to $21 \%$.

Namely for samples, according to the level loading, the effect of strengthening decreases by 2.8 times, from $45 \%$ to $16 \%$, so to perform strengthening at the level of more than 0.5 is impractical.

The results of the comparative analysis of the shear strength of strengthening RC beam on the shear are shown in Table 1. 
Table 1. The ultimate limit state (ULS) inclined cross sections of testing beams.

\begin{tabular}{|c|c|c|c|c|c|c|}
\hline Types of beams & $\begin{array}{l}\text { Types of the } \\
\text { beams' cross } \\
\text { section }\end{array}$ & $\begin{array}{c}\text { Cross } \\
\text { section } \\
b \times h \mathrm{~mm} .\end{array}$ & $\begin{array}{l}\text { Span of } \\
\text { the } \\
\text { beam } l_{0} \\
\text { mm }\end{array}$ & $\begin{array}{c}\text { Experimental } \\
\text { shear strength } \\
V_{E d}^{\exp }, \mathrm{KN}\end{array}$ & $\begin{array}{c}\text { Average } \\
\text { experimental } \\
\text { shear load, } \\
V_{E d}^{\exp }, \mathrm{\kappa N}\end{array}$ & $\begin{array}{c}\text { Increasing } \\
\text { shear } \\
\text { strength } \\
\frac{V_{e d}}{V_{e d}^{B O 1.1}}\end{array}$ \\
\hline \multirow{2}{*}{ BO 1.1} & BO 1.1.1 & \multirow{2}{*}{$201 \times 101$} & 1900 & 97 & \multirow{2}{*}{95} & \multirow{2}{*}{ - } \\
\hline & BO1.1.2 & & 1550 & 93 & & \\
\hline \multirow{2}{*}{ BSC 1.1-0 } & BSC 1.1.1-0 & \multirow{2}{*}{$199 \times 100$} & 1900 & 130 & \multirow{2}{*}{137.5} & \multirow{2}{*}{1.45} \\
\hline & BSC 1.1.2-0 & & 1650 & 145 & & \\
\hline \multirow{2}{*}{ BSC $1.2-0.3$} & BSC 1.2.1-0.3 & \multirow{2}{*}{$200 \times 100$} & 1900 & 126 & \multirow{2}{*}{120} & \multirow{2}{*}{1.26} \\
\hline & BSC 1.2.2-0.3 & & 1650 & 117 & & \\
\hline \multirow{2}{*}{ BSC $1.3-0.5$} & BSC 1.3.1-0.5 & \multirow{2}{*}{$201 \times 98$} & 1900 & 116 & \multirow{2}{*}{110} & \multirow{2}{*}{1.16} \\
\hline & & & 1650 & 114 & & \\
\hline
\end{tabular}

The inclined crack width $w_{\max }=0.4 \mathrm{~mm}$ was the criterion for serviceability limit state. The results of the experimental data of the shear strength for serviceability are in Table. 2.

Table 2. The serviceability limit state (SLS) inclined cross sections of testing beams.

\begin{tabular}{|c|c|c|c|c|c|}
\hline Types of beams & $\begin{array}{l}\text { Types of the } \\
\text { beam cross } \\
\text { section }\end{array}$ & $\begin{array}{c}\text { Maximum } \\
\text { inclined } \\
\text { crack width, } \\
\text { mm }\end{array}$ & $\begin{array}{l}\text { Experimental } \\
\text { shear strength } \\
V_{E d}^{\exp }, \mathrm{KN}\end{array}$ & $\begin{array}{c}\text { Average } \\
\text { experimental shear } \\
\text { load, } \\
V_{E d}^{\exp }, \mathrm{\kappa N}\end{array}$ & $\begin{array}{l}\text { Increasing } \\
\text { shear strength } \\
\frac{V_{e d}}{V_{e d}^{B O 1.1}}\end{array}$ \\
\hline \multirow{2}{*}{ BO 1.1} & BO 1.1.1 & \multirow{8}{*}{0.4} & 80 & \multirow{2}{*}{80} & \multirow{2}{*}{ - } \\
\hline & BO 1.1.2 & & 80 & & \\
\hline \multirow{2}{*}{ BSC 1.1-0 } & BSC 1.1.1-0 & & 120 & \multirow{2}{*}{110} & \multirow{2}{*}{1.38} \\
\hline & BSC 1.1.2-0 & & 100 & & \\
\hline \multirow{2}{*}{ BSC 1.2-0.3 } & BSC 1.2.1-0.3 & & 100 & \multirow{2}{*}{100} & \multirow{2}{*}{1.25} \\
\hline & BSC 1.2.2-0.3 & & 100 & & \\
\hline \multirow{2}{*}{ BSC 1.3-0.5 } & BSC 1.3.1-0.5 & & 90 & \multirow{2}{*}{90} & \multirow{2}{*}{1.13} \\
\hline & BSC 1.3.2-0.5 & & 90 & & \\
\hline
\end{tabular}

Character and value of increasing shear strength by SLS for all samples reinforced composite system is close in meaning to ULS. But the fixed disclosure of limit crack width $w_{\max }=0.4 \mathrm{~mm}$ inclined at $20 \mathrm{kN}$ was lower than the loss of the shear strength of inclined section. Also, the maximum values of crack opening constitute the $0.5 \ldots 0.6 \mathrm{~mm}$ at sample BSC 1.2-0.3 and BSC 1.1-0 and $0.7 \mathrm{~mm}$ at BSC 1.3-0.5. On the surface of the material limit the width crack disclosure constitutes the $w=0.2 \mathrm{~mm}$, which is considerably less than the limit one.

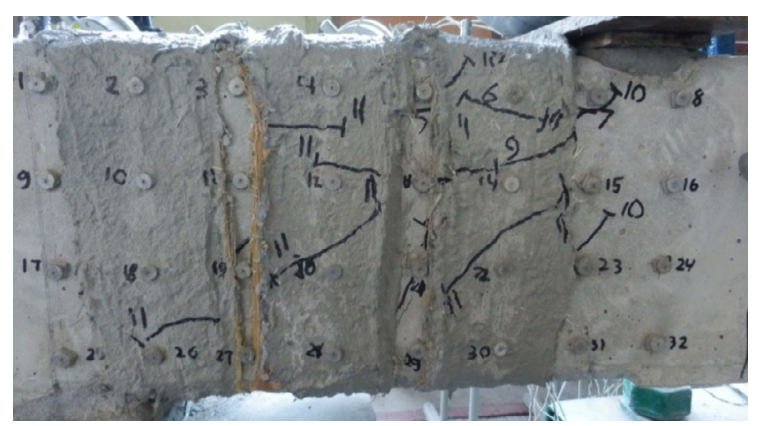

Fig. 8. Distribution of cracks on the surface of the strengthening 
The sharp increase in the width of the crack opening exposing the composite materials is observed with physical destruction in specimens. It should be noted that the inclined crack width was measured on the concrete surface between strengthening elements. In the cover layer of strengthening material opening width of cracks was less than $0.25 \mathrm{~mm}$, but on the surface of a there were a mesh of cracks (Fig. 8).

\section{Conclusions}

1. The maximum effect of increasing the shear strength (ULS) is $45 \%$ for samples strengthened without initial loading. In accordance with the increase of the initial loading the strengthening effect decreases. For beams reinforced at the level of $0.3 V_{e d}$ the effect decreases to $21 \%$ and for BSC $1.3-0.5$ to $16 \%$.

2. Character and value of increasing shear strength by SLS for all samples reinforced composite system is close in meaning to ULS. But the fixed disclosure of limit crack width $w_{\max }=0.4 \mathrm{~mm}$ inclined at $20 \mathrm{kN}$ was lower than the loss of its shear strength. The maximum effect of ULS is $38 \%$ for samples strengthened without initial loading. For beams reinforced at the level of $0.3 V_{e d}$ the effect decreases to $25 \%$ and for BSC $1.3-0.5$ to $13 \%$.

3. For samples, according to the level loading, the effect of strengthening falls to $2.8-2.9$ times, from $45 \%$ to $16 \%$ and from $38 \%$ to $13 \%$, so to perform strengthening beams like were tested at the level of more than 0.5 is unpractical.

4. This peculiarity that strengthening effect depends on loadings level should be considered when we design the strengthening systems.

\section{References}

1. E. David, C. Djelal, F. Buyle-Bodin, 2nd Int. PhD Symposium in Civil Engineering, 1 (1998)

2. L. Ombers, Compos. Struct. №94, 143 (2011)

3. R.S. Chavan, P.M. Pawar, IJERA, Vol.3, Issue 6, 554 (2013).

4. E. A.-M. Ahmed, Shear behavior of concrete beams reinforced with fibre-reinforced polimer (PFR) stirrups : dis. doctor sciences: 05.23.01, 291 (2009).

5. A. Alzate, A. Arteaga, A. de Diego, D. Cisneros, R. Perera, Mater. Construcc., 63(310) 251 (2013).

6. http://english.ruredil.it/Ruredil_Prodotti_chimici_per_edilizia/cataloghi.asp

7. P. Vegera, R. Khmil, Z. Blikharskyy, JCEEA, T. XXXII, z. 62 (nr 4/2015), 447 (2015).

8. National Standard of Ukraine, Concrete and reinforced concrete structures: DBN B.2.6 - 98: 2009, 84 (2011).

9. Europian Norm, EN 1992-1-1:2004 Eurocode 2: Design of concrete structures - Part 1-1: General rules for buildings, 225 (2004).

10. Externally bonded FRP reinforcement for RC structures. Technical report, FIB, 130 (2001). 